\title{
Research and Practice of Digital Signal Processing Based on the Comprehensive Teaching Mode
}

\author{
Xiaojuan Wei \\ School of Electrical Engineering \\ Northwest Minzu University \\ Lanzhou, China \\ weixiaojuan925@126.com
}

\begin{abstract}
Digital Signal Processing is an important specialized course for undergraduates majoring in electrical information. This course has a mix of very abstruse theory, many abstract concepts, scientific methods and mathematical knowledge, so it is quite difficult for students to master it. In terms of the learning status quo of the major students in our university, they have a week foundation for mathematics, so they face quite a few barriers in learning process and show a low interest in learning this course. They master and comprehend little knowledge in the process of learning. Therefore, the paper conducted a reform on the teaching methods \& content, practiceoriented teaching and classroom teaching models, so as to help students to comprehend and master the basic concepts, basic principles and basic analysis methods of the course, and fully improve their ability to apply what they learn to solve practical problems and their innovative ability in practice.
\end{abstract}

Keywords-Digital Signal Processing; diversified teaching methods; diversified experimental teaching; comprehensive Teaching Mode;

\section{INTRODUCTION}

In recent years, with the rapid development of digital and information technology and the expansion in the application range, it is imperative to conduct a reform on information technology course. In the teaching practice of the course, it is found that traditional teaching methods fail to help students to understand and master the basic concepts, principles and analysis methods in the course and to improve their ability to apply what they learn to solve practical problems. Traditional teaching methods of the course lay more emphasis on imparting theories, and most of the content of the course contains abstract concepts and theories, most of which require students to make deduction based on mathematic knowledge [1]. However, most students have a week foundation for mathematics (especially Laplace transform, Fourier transform and z-transform), so they meet a lot of obstacles in the learning process and show little interest in learning this course with bad academic performance. Most students have a smattering of knowledge of some important theories of the course; even if they know usage of these theories, it is difficult for them to apply such theories to practice. The disconnection between course and practice goes against the goal of education. Therefore, in order to improve classroom teaching efficiency,

This work is supported by Fundamental Research Funds for Gansu Province Science Foundation for Youths (Grant No.17JR5RA281), by National Natural Science Foundation of China (Grant No.61463046) and by the Teaching Reform Project of Northwest Minzu University for of China. broaden students' knowledge scope and improve students ability in system design and practice, this paper carries out innovation and experiment in the following aspects, including introducing modern teaching methods and the latest teaching research and scientific research results, reforming practiceoriented teaching methods and so on. Such innovation and experiment play a key role in helping students to enhancing their ability in acquiring and applying new knowledge, improving their quality, so that they can adapt to the rapid development pace in electronic information.

\section{ADOPTING DIVERSIFIED TEACHING METHODS AND REFORMING TEACHING MODE}

There are a lot of concepts in digital signal processing, which are very abstract with complicated formula derivation, so it is not easy to understand. Many teaching methods, including blackboard writing, multimedia teaching, providing answers and explanation through online communications, etc., are adopted and a multimedia support system is also developed to give full play to the advantages in network resources and modern teaching methods.

This paper adopts a brand new teaching method, which combines presentation, analysis with calculation, to guarantee teaching quality, so that students can have a solid foundation of basic knowledge and good application of such knowledge. Teachers should constantly explore new teaching methods; make full use of teaching resources and reform teaching means. They should make computer-aided instruction with PowerPoint, Flash, MATLAB and other program language, simply mathematical derivation process, and present the content of "Digital Signal Processing" in the classroom with representative and living examples in a dynamic way. A combination of expression, analysis and calculation can be used to instruct the course of "Digital Signal Processing", present the boring theories in a vivid way and improve students' ability to apply relevant theories and software to solve practical problems. Such new method can get twofold results with half the effort.

In the process of teaching, teachers should transform the monotonous teaching pattern into diversified teaching pattern. For example, Java, Flash, Photoshop, Authorware and other tools can be used to make animation and visualize abstract concepts by presenting theoretical concepts with vivid images and animation. MATLAB can also be used to visualize abstract 
concepts and demonstrate the physical significance and the physical realization approaches of design methods. Slides, audio, video and other media can also be used to conduct interactive teaching in a vivid and straightforward way, so as to facilitate students' understanding and memorization of knowledge, motivate them to learn actively with interest, broaden their thinking scope, and implement teaching in a vivid way. Moreover, flash animation can be used to present the Nyquist sampling theorem. In addition to the explanation of teachers, the content about sampling frequencies lower than, equal to and higher than double of the maximum frequency component of the signal is demonstrated one by one by means of the flash animation effect, so as to explain the reasons for the sampling frequency being at least higher than or equal to the double of the maximum frequency component of the signal. The visualized demonstration with images and concise explanation can help students to understand and memorize the sampling theorem in a better way, thoroughly get acquainted with the knowledge and stimulate their interest in learning the course.

\section{INTEGRATE AND UPDATE TEACHING CONTENT, AND BRING IN TEACHING RESEARCH AND SCIENTIFIC RESEARCH RESULT}

The "Signal and Systems" and the "Digital Signal Processing" are partially overlapping. As the discrete signal and system analysis in the course of "Signal and Systems" overlap with most of the content in "Digital Signal Processing", so the two courses consume excessive class hours. Since there is no organic cooperation between the two courses, so no organic integration is formed. Based on the summary of longterm teaching experience, the course content is summarized and integrated. In the course of "Signal and Systems", emphasis is laid on the analysis of continuous signal and time domain of the system; while the "Digital Signal Processing" mainly focuses on the discrete signal and the application of the system. Therefore, teaching reform is made to optimize the teaching content of "Digital Signal Processing"[2-3].

"Digital Signal Processing" highlights the digital methods and technology, and only review the analysis basis of discrete signal and system, time domain sampling theorem and frequency domain sampling theorem in a brief way. The key content of the course contains Discrete Fourier Transform (DFT) \& the application, fast implementation of DFT (FFT arithmetic), the structure of digital filter, the design of IIR and FIR filter, limited word-length in the digital signal processing and so on and the teaching content focuses on engineering practice [4-5].

Through the update of course content, teachers should focus on the presentation patterns of knowledge, and strive to improve students cognitive ability and autonomous learning ability in the process of instruction. They should also focus on the application of engineering knowledge, guarantee the completeness and preciseness of theory content, abandon the tedious and boring theoretical derivation, and instruct relevant knowledge to students based on the different features, cognitive laws and learning habits of students. Moreover, they should actively bring in teaching research and scientific research results, strengthen the combination of theory with engineering practice. The course of "Digital Signal Processing" has many mathematical formulas and abstract physical significance, so it is not easy for students to master and use such knowledge. If advanced multimedia technology and other teaching technology can be used in the teaching process, and engineering problems can be discussed in the student projects, it might be an effective attempt to cultivate innovative talents. The emphasis of the course should be laid on the application of digital signal process to enable students to master the implementation technology of digital signal processing. This is also the goal of the course. In the teaching process, a combination of theory with practical engineering knowledge means the strict theoretical system and vivid engineering examples. Teachers should focus on the introduction to basic concepts and basic methods, bring in the concept of engineering application in the theoretical derivation, and help students to strengthen their memory of theories by means of example analysis. Therefore, teachers should combine theoretical knowledge with engineering practice, teaching with scientific research, instill engineering ideas into the mind of students, encourage students to realize the important application of the theories in a visualized way, guided them in scientific and technological activities, and improve their engineering ability and practical ability in the process of teaching basic concepts and relevant theories. For example, image denoising and spectrum analysis of signal and systems are a typical example in the Fourier Transform; as for the features of frequency shift in the Fourier Transform, communications system is taken as an example to illustrate the shift process of frequency spectrum; the application of sampling theorem in signal sampling and so on. As for the teaching pattern of the course, teachers can explore key knowledge points of digital signal processing in the examples in the daily life and engineering, which can help students to arouse their enthusiasm and interest in learning.

\section{DIVERSIFICATION IN EXPERIMENTAL TEACHING AND REFORM OF PRACTICAL TEACHING SYSTEM}

Experimental teaching can not only strengthen students' learning of theories, but also improve students' ability to make comprehensive application of what they learn, analyze and solve problems independently, and make innovation. Teachers should help engineering students to meet the quality requirements of engineering education, promote diversification of practice-oriented teaching, and build a practice-oriented teaching system to promote students' comprehensive and coordinated development in knowledge, ability and quality [6].

Firstly, the traditional experiment course should be transformed into real practice-based experiment course, which contains three types of experiments, including basic verification experiment, comprehensive experiment and design-based experiment, so as to meet the demands of various students at different levels.

The basic verification experiment is to verify what knowledge students' have learn in the theory course, help students to understand and master the basic theories learned in class, enable them to use MATLAB software to show discrete signals or systems, analyze and treat signals or systems, including discrete-time signal analysis, LTI system frequencydomain analysis, spectrum analysis by means of FFT and Z- 
transform. The comprehensive experiment refers to the experiment with content relating to comprehensive knowledge of the course, such as analog filter design and digital filter design. These experiments aim to improve students' ability to make a comprehensive application of what they have learned. Design-based experiment refers to the experiment, which students can design experiment programs and implement such programs under certain experiment requirements and conditions [7-8]. In the design-based experiment, teachers should first give students experiment titles and specific technical indicators; students should first inquire the relevant information and determine the experiment programs in accordance with the requirements; students should design their own procedure and complete the experiment; then they should write an experiment report. The design of FIR digital filter and IIR digital filter design mainly aim to help students to improve their design ability, innovation ability and initiative.

With the gradual development of the course content, teachers can build a set of practice system, which includes experimental platform, curriculum design, open laboratory and virtual experimental platform.

1) Experimental platform. Advanced development platform of digital signal processor and the software platform of MATLAB will be brought in the practice-oriented teaching to enhance the connection with current engineering development and improve students' adaptability to actual work.

2) Curriculum design. The Digital Signal Processing course contains a variety of operations on discrete signals, such as addition, multiplication, reversal, translation, convolution, circumferential convolution, FIR \& IIR filter design and fast Fourier transform. These operations can be classified and students should be allowed to use MATLAB program language to design the curriculum in the entire teaching process of the Digital Signal Processing. For example, students should be encouraged to deal with a specific case of signal processing (voice signal analysis and processing, signal frequency division multiplexing, simple processing of special effects of voice signal, such as delay and reverberation, filter processing of noisy voice signal, etc.), so as to strengthen their understanding and practical ability in applying the basic filter theories, and implement simple signal processing system. If curriculum design is not arranged, then this part can be replaced by comprehensive design experiment for students to do exercises.

3) Add open experiment and build a virtual experiment platform. Students can not only use their spare time to develop such platform, but also form an experiment group to develop the open experiment in the laboratory. Such arrangement can help students to master the application of digital signal processing technology, transform theory-oriented learning to experimental skill learning and innovative research. Network resources can also be used to build virtual digital signal processing lab, so as to provide students with an environment with rich resources for learning digital signal processing, reduce the wastage of experimental tools; moreover, the configuration is flexible with good scalability and short development cycle.

\section{CONSTRUCTION AND PERFECTION OF WEB-BASED TEACHING RESOURCES}

Due to the limitation of class hours, the content of the "Digital Signal Processing" cannot be all instructed in the classroom. Teachers can use the convenient and efficient network resources to encourage students to make self-study of some content after school. In order to meet the actual teaching demand of the "Digital Signal Processing", network resources should be used to build an open and interactive online learning platform for the course based on the Fanya teaching platform of the university and in accordance with the features of the teaching content, teaching requirements and students. This learning platform provides a variety of learning resources, including course outline, teaching plans, multimedia courseware, animation, exercises, experimental guidance and research-based learning in the network, etc.; moreover, the link of excellent national and provincial course examples of "Digital Signal Processing" should also be added to the course website, so that students can learn from other excellent teachers; other links to forums and websites in relation to this course shall also be provided on this website to broaden students' vision. The combination of classroom teaching and extracurricular self-study can enable students to learn the course relying on the textbooks and other resources, in the school and outside the school, so that students can have more resources for improving their innovation ability.

It is found that the web-assisted teaching can not only encourage students to make autonomous learning, explore new knowledge and participate in practice, but also help them to improve their ability to collect and process information, exchange and cooperate with others, learn new knowledge, make self-study and cooperative learning.

\section{CONCLUSIONS}

According to years of feedback from students, the teaching content of the course should be closely linked with the actual situation to meet the objective requirements for talent cultivation. The combination of diversified teaching methods with modern educational techniques can create a virtual real world, which supports situational teaching, transforms difficulties into simpleness, and quick teaching into slow teaching, enable students to learn abstract theories in an easy way. The practice part can motivate students to learn actively and give full play to their innovative thinking, so the practice part plays a key role in improving students' knowledge system.

\section{ACKNOWLEDGMENT}

This work is supported by Fundamental Research Funds for Gansu Province Science Foundation for Youths (Grant No.17JR5RA281), by National Natural Science Foundation of China (Grant No.61463046) and by the Teaching Reform Project of Northwest Minzu University for of China.

\section{REFERENCES}

[1] LIU Hong-xiu, LI Hong-bo, LI-Jie, "The Teaching Reform Research of Digital Signal Processing Based on the Comprehensive Mode," Journal of EEE, vol. 37 No.5, pp. 38-40, Oct. 2015. 
[2] Manolaki sD G, Ingle V K , Kogon S M .St atistical and Adaptive Signal Processing[M] . Beijing: tsinghua university press, pp. 1-30. 2003

[3] Sanjit K Mitra.Digital Signal Processing-A Computer-Based Method [M]. The Second Edition . Beijing: tsinghua university press, pp. 12-40, 2001.

[4] Oppenheim A V, Schafer R W, Buck J R.Discrete-Time Signal Processing(The Second Edition)[ M] . Beijing: tsinghua university press, pp. 693-754, 2005.

[5] Roberto Cristi.Modern Digital Signal Processing [M] . Beijing: Machinery Industry Press , pp. 1-25, 2005.
[6] ZHU Jin-xiu, ZHANG Zhuo, ZHU Chuang-ping, "Research on Practical Teaching Method for Digital Signal Processing Course," Research and Exploration in Laboratory, vol. 33 No.9, pp. 180-183, Sep. 2014.

[7] Wang Qiu-sheng, Yuan Hai-bin, "Teaching Probe and Practice to

[8] Digital Signal Processing," Journal of EEE,vol. 30 No.8, pp. 87-89, Oct. 2008.

[9] ZHU Jin-xiu, ZHANG Zhuo, ZHU Chuang-ping, "Experimental Teaching Research and Practice of Digital Signal Processing Course," Research and Exploration in Laboratory, vol. 27 No.5, pp. 96-98, May. 2008. 